\title{
Radiotherapy in patients with distant metastatic breast cancer
}

\author{
Kirsten Steinauer ${ }^{1,2}$, Markus Wolfram Gross ${ }^{3}$, Dorothy Jane Huang ${ }^{4}$, Serenella Eppenberger-Castori ${ }^{5}$ and Uwe Güth ${ }^{2,4,6^{*}}$
}

\begin{abstract}
Background: The study evaluates frequency of and indications for disease-related radiotherapy in the palliative breast cancer (BC) situation and analyzes in which phase of the palliative disease course radiotherapy was applied.

Patients \& methods: 340 patients who developed distant metastatic disease (DMD) and died (i.e. patients with completed disease courses) were analyzed.

Results: 165 patients (48.5\%) received palliative radiotherapy (255 series, 337 planning target volumes) as a part of palliative care. The most common sites for radiotherapy were the bone ( 217 volumes, $64.4 \%$ of all radiated volumes) and the brain (57 volumes, 16.9\%). 127 series (49.8\%) were performed in the first third of the metastatic disease survival (MDS) period; 84 series (32.8\%) were performed in the last third. The median survival after radiotherapy was 10 months. Patients who had received radiation were younger compared to those who had no radiation (61 vs. 68 years, $p<0.001)$ and had an improved MDS ( 26 vs. 14 months, $p<0.001$ ). Compared to rapidly progressive disease courses with short survival times, in cases where effective systemic therapy achieved a longer MDS ( $\geq 24$ months), radiotherapy was significantly more often a part of the multimodal palliative therapy (52.1\% vs. $37.1 \%, p=0.006)$.

Conclusions: In a cohort of $\mathrm{BC}$ patients with $\mathrm{DMD}$, nearly one half of the patients received radiotherapy during the palliative disease course. In a palliative therapy approach, which increasingly allows for treatment according to the principles of a chronic disease, radiotherapy has a clearly established role in the therapy concept.
\end{abstract}

Keywords: Breast cancer, Distant metastases, Palliative radiotherapy

\section{Introduction}

In Western countries, approximately $5-10 \%$ of all breast cancer $(\mathrm{BC})$ patients present with distant metastases at initial diagnosis (primary metastatic disease). Depending on prognostic factors, up to $30 \%$ of node-negative and up to $70 \%$ of node-positive $\mathrm{BC}$ patients develop distant metastases during the course of their illness (secondary metastatic disease) [1]. The prognoses and clinical courses of patients with distant metastatic BC vary considerably depending on host and tumor characteristics. Once distant metastases occur, BC remains a treatable condition but is no longer considered curable [1-3]. In this situation, radiotherapy might be performed with palliative intention

\footnotetext{
* Correspondence: uwe.gueth@unibas.ch

2Breast Center "SenoSuisse", Brauerstrasse 15, Winterthur CH-8401,

Switzerland

${ }^{4} \mathrm{UHB}$, Department of Gynecology and Obstetrics, Spitalstrasse 21, Basel

$\mathrm{CH}-4031$, Switzerland

Full list of author information is available at the end of the article
}

and the primary goals of treatment include prevention and palliation of symptoms, maintenance or improvement of quality of life and prolongation of survival [4-6].

In the literature, there exists a large amount of information on radiotherapy during the disease course of metastatic BC. However, most of the published studies focused on the effect of different fractionation regimens and total radiation doses in the treatment of bone and brain metastasis, and spinal compression [4,7-9].

In a recent review, Budach evaluated the role of radiotherapy in the palliative $\mathrm{BC}$ situation in a more general approach and examined the various interventions in different anatomic sites [4]. This general approach, however, had never been applied to an institutional series of metastatic $\mathrm{BC}$ patients until now. To our knowledge, our study is the first to systematically evaluate how the available radiotherapy options were actually clinically implemented in an unselected cohort of $\mathrm{BC}$ patients with distant metastatic

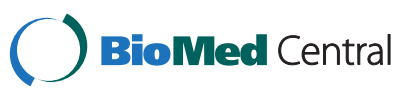

(c) 2014 Steinauer et al.; licensee BioMed Central Ltd. This is an Open Access article distributed under the terms of the Creative Commons Attribution License (http://creativecommons.org/licenses/by/4.0), which permits unrestricted use, distribution, and reproduction in any medium, provided the original work is properly credited. The Creative Commons Public Domain Dedication waiver (http://creativecommons.org/publicdomain/zero/1.0/) applies to the data made available in this article, unless otherwise stated. 
disease (DMD) over a longer period of time (1990-2012). By doing so, the main questions to be answered were: how often did patients receive $\mathrm{BC}$-related radiotherapy in a situation considered to be incurable, at which metastatic sites, at what age, and in which phase of the disease course?

\section{Patients and methods}

Data from the prospective relational Basel Breast Cancer Database (BBCD), which includes all newly diagnosed primary invasive $\mathrm{BC}$ cases treated at the University Women's Hospital Basel, Switzerland since 1990, provided the basis for this study. This institution comprises the largest breast center in the canton of Basel and is representative of the population of the region. For this study, data from all female patients who were diagnosed with BC up to and including 2009 was analyzed ( $\mathrm{n}=1459)$.

During this 20-year period, 92 patients (6.3\%) had DMD at initial diagnosis, or in other words, had primary metastatic disease (PMD). In 2011, with the exception of 37 patients who were lost to follow-up $(2.5 \%$ of the entire study group), outcome information was available for all patients recorded in the BBCD. As of March 2011, 277 patients $(20.3 \%$ of all patients who had stage I-III disease at initial $\mathrm{BC}$ diagnosis) had developed distant metastases over time, or in other words, had secondary metastatic disease (SMD). The median time between initial $\mathrm{BC}$ diagnosis and first diagnosis of DMD was 38.5 months (range: 2-215 months).

Out of 369 patients with confirmed distant metastatic $\mathrm{BC}$, we were able to obtain information regarding the time of diagnosis of metastatic disease and date of death but we did not have complete information about the disease course and palliative therapy details for six patients (PMD, $\mathrm{n}=1$; SMD, $\mathrm{n}=5$ ). Thus, these patients were not considered for analysis, and ultimately 363 patients were included in the study (Table 1).

The patients in this cohort were followed until death. Patients who remained alive were followed until January 2013, thus all surviving patients had a follow-up time of at least 24 months. The outcome status of the cohort ( $\mathrm{n}=363$ ) was as follows: 1 ) died of metastatic BC: 316 patients (87.1\%); 2) died of other causes: 24 patients $(6.6 \%)$; 3) alive with metastatic disease: 20 patients $(5.5 \%)$; and 4) alive, no evidence of disease: 3 patients $(0.8 \%$, Table 1).

In order to analyze radiation oncology procedures during the palliative therapy course, we examined only the 340 patients who ultimately died of their metastatic disease (PMD, $n=78$; SMD, $n=262$ ). In other words, we analyzed only completed disease and treatment courses (Table 1). The clinicopathologic features of these 340 patients are listed in Table 2.
Table 1 Disease-related radiotherapy in breast cancer patients with distant metastatic disease

\begin{tabular}{lc}
\hline Variable & $\mathbf{n}(\%)$ \\
\hline Entire cohort of the BBCD & 1459 \\
Patients with distant metastases (DM) & $369(25.3)$ \\
$\quad$ PMD: DM at initial diagnosis & $92(6.3)$ \\
$\quad$ SMD: DM developed during the & $277(19.0)$ \\
$\quad$ course of the illness & 363 \\
$\begin{array}{l}\text { Patients with complete information } \\
\text { about disease and therapy course. }\end{array}$ & $23(6.3)$ \\
$\quad$ Last follow-up: alive' & $340(93.7)$ \\
$\quad \begin{array}{l}\text { Study cohort: patients who died, i.e. patients } \\
\text { with completed disease and therapy courses }\end{array}$
\end{tabular}

Study cohort

A. Breast cancer-related radiotherapy

B. No radiotherapy

$175(51.5)$

Breast cancer-related radiotherapy

Number of patients 165

Number of series 255

median/mean (range) 1/1.6 (1-5)

Number of planning target volumes 337

median/mean (range)

$2 / 2.0(1-8)$

Metastatic sites and radiation volumes 337

Breast and locoregional lymph nodes 35 (10.4)

- primary tumor region after surgery (PMD) 8 (2.4)

- primary breast tumor without surgery (PMD) $3(0.9)$

- recurrence at the chest wall, no surgery $6(1.8)$

- chest wall after surgery for local recurrence $1(0.3)$

- recurrence at locoregional lymph nodes $17(5.0)$

Bone

- vertebrae and osseous pelvis

$137(40.7)$

- other sites $\quad 80(23.7)$

Brain $\quad 57(16.9)$

Other locations 28 (8.3)

- skin/soft tissue $13(3.8)$

- mediastinum $6(1.8)$

- eye $3(0.9)$

- lung $3(0.9)$

- cervical lymph nodes $2(0.6)$

- liver $1(0.3)$

BBCD: Basel Breast Cancer Database; DM: distant metastases; PMD: primary metastatic disease; SMD: secondary metastatic disease.

${ }^{1}$ Last follow-up: January 2013. Three patients were alive with no evidence of disease. The long-time survival after pathologically confirmed distant metastatic disease of these three patients was as follows: i) 204 months after diagnosis of bone metastases, ii) 209 months after diagnosis of bone and lung metastases, iii) 230 months after diagnosis of lung metastases. Detailed description of these three cases in: [10]. 
Table 2 Clinicopathologic and outcome characteristics between a cohort of 340 breast cancer patients with distant metastatic disease and completed disease courses; A. patients who received breast cancer-related radiotherapy during palliative situation, $B$. no radiotherapy

\begin{tabular}{|c|c|c|}
\hline Variable & $\begin{array}{c}\text { Group A } \\
\text { Radiotherapy } \\
n=165 \text { (\%) }\end{array}$ & $\begin{array}{c}\text { Group B } \\
\text { No radiotherapy } \\
n=175(\%)\end{array}$ \\
\hline \multicolumn{3}{|l|}{$\begin{array}{l}\text { AJCC/UICC TNM stage } \\
\text { at initial diagnosis }\end{array}$} \\
\hline Stage I & $17(10.3)$ & $16(9.1)$ \\
\hline Stage II & $56(34.0)$ & $60(34.3)$ \\
\hline Stage III & $54(32.7)$ & $59(33.7)$ \\
\hline Stage IV & $38(23.0)$ & $40(22.9)$ \\
\hline \multicolumn{3}{|l|}{ Histologic subtype $^{1}$} \\
\hline Ductal invasive & $130(79.3)$ & $133(76.9)$ \\
\hline Lobular invasive & $30(18.3)$ & $32(18.5)$ \\
\hline Rare types & $4(2.4)$ & $8(4.6)$ \\
\hline Not available & 1 & 2 \\
\hline \multicolumn{3}{|l|}{ Grading $^{1}$} \\
\hline $\mathrm{G} 1 / 2$ & $54(34.6)$ & $57(35.2)$ \\
\hline G3 & $102(65.4)$ & $105(64.8)$ \\
\hline Not available & 9 & 13 \\
\hline \multicolumn{3}{|l|}{ Hormonal receptor status ${ }^{1}$} \\
\hline Positive & $116(74.8)$ & $125(74.4)$ \\
\hline Negative & $39(25.2)$ & $43(25.6)$ \\
\hline Not available & 10 & 7 \\
\hline HER2 status, 2002-2009 & $n=40(\%)$ & $n=57(\%)$ \\
\hline Positive & $16(40.0)$ & $10(17.9)$ \\
\hline "Triple-negative" carcinoma & $6(15.0)$ & $12(21.4)$ \\
\hline Not available & - & 1 \\
\hline \multicolumn{3}{|l|}{ Metastatic disease survival } \\
\hline$<12$ months & $80(45.7)$ & $46(27.9)$ \\
\hline 12-24 months & $33(18.9)$ & $34(20.6)$ \\
\hline 25-48 months & $43(24.5)$ & $58(35.1)$ \\
\hline$>48$ months & 19 (10.9) & $27(16.4)$ \\
\hline
\end{tabular}

AJCC: American Joint Committee on Cancer; UICC: International Union Against Cancer $[11,12]$

'Histologic subtype, grading, hormonal receptor status and HER2 status were measured in primary breast tumor.

${ }^{2}$ Because HER-2 status has been routinely assessed for all patients since 2002, we only report data from 2002-2009 for this particular characteristic.

\section{Radiotherapy: definition of series and planning target volumes}

For each case, the number of radiotherapeutic interventions (series) and the respective planning target volumes (ptv) were recorded. For example, a patient received radiotherapy for bone metastases in June 2005. In this first treatment series, two ptv were irradiated: the humerus with 15 Gy and a section of the thoracic and lumbar spine (T4-L1) with 30 Gy. In a second series in January 2006, the brain (30 Gy) and two further bone volumes- right femur (24 Gy) and a segment of the cervical and thoracic spine (C3-T1, $30 \mathrm{~Gy})$ - were irradiated. In this particular case, we recorded two radiotherapy series and five ptv.

\section{Ethics committtee}

The study design and data collection methods were approved by our institutional review board (Ethikkommission beider Basel).

\section{Statistical analysis}

Since the ages of all subsets were found to have almost a Gaussian distribution, statistical differences between age of the subsets were analyzed using the unpaired $t$-test. The radiotherapeutic approaches and the survival times after radiotherapeutic interventions were compared by means of the nonparametric Wilcoxon-Test. Comparisons between nominal parameters were made with the Fisher exact test. In all statistical tests the level of significance was $\mathrm{p}<0.05$. Statistical evaluations were performed with Splus software (Version 6.1, Insightful Corporation, Seattle, WA, USA).

\section{Results}

From a study cohort of 340 patients, 165 received radiotherapy as a part of palliative care. (48.5\% of all patients with distant metastases and completed therapy and disease courses; Table 1).

\section{Radiotherapy vs. no radiotherapy}

The patients who received radiotherapy during the palliative situation were significantly younger compared to those who had had no radiation (median age: 61 years [range: 30-89] vs. 68 years [range: 28-94], p < 0.001).

Patients who had received palliative radiation had a significantly improved metastatic disease survival (MDS; median: 26 months [range: 1-126] vs. 14 months [range: $0.5-102], \mathrm{p}<0.001)$. When one compares both groups with regard to a MDS of $\geq 24$ months, a significantly higher percentage of patients who had radiation during the palliative disease course reached this mark compared to patients who had no radiation $(52.1 \%$ vs. $37.1 \%, \mathrm{p}=0.006)$.

\section{Radiotherapy within palliative therapy and disease course of metastatic BC}

Among the 165 patients who received radiotherapy, a total of 255 series with 337 ptv were applied (Table 1). The most common sites for radiotherapy were the bone (217 volumes, $64.4 \%$ of all radiated volumes) and the brain (57 volumes, 16.9\%). Thirty-five ptv (10.4\%) were applied in different locations with regard to the breast/ chest wall, including regional lymph nodes. A further 28 volumes $(8.3 \%)$ were applied to other locations (skin/soft 
tissue, mediastinum, eye, lung, cervical lymph nodes, liver; Table 1).

Table 3 shows the distribution of the metastatic sites. Bone metastases, which were diagnosed in nearly two thirds of the cases (69.6\%), were the most frequent metastatic location, followed by metastases of the lung (51.5\%), liver (43.8\%), lymph nodes (28.5\%) and brain (18.8\%). With regard to the occurrence of metastatic lesions, brain (85.9\%) and bone metastases (45.6\%) were the most frequent radiated locations (Table 3). When metastases of the lung and the liver were diagnosed, they were treated with radiotherapy comparatively rarely $(\leq 1 \%)$.

Patients who had radiotherapy during their palliative disease course had a median age at the time of procedure of 60 years (mean age: 60.6 years, range: 32-89 years). There were no significant differences between the entire study group and patients who had radiotherapy for bone metastases (mean age: 60.5 years, $\mathrm{p}=0.841$ ); compared to the entire study cohort, patients who had radiotherapy for brain metastases were significantly younger (mean: 55.4 years, $\mathrm{p}=0.011)($ Table 4$)$.

One hundred and twenty-seven out of 255 radiotherapy series (49.8\%) were performed in the first third of the survival period (i.e. period of MDS); approximately one third of the procedures were performed in the last third ( $\mathrm{n}=84$; Table 4). The median survival after radiotherapy was 10 months (range: 0.2-123 months) (Table 4). Patients who were radiated for bone metastases had a significantly longer survival time after the radiotherapeutic intervention compared to patients who had radiation for brain metastases (median: 14 months vs. 5 months, $\mathrm{p}<0.001$, Table 4).

Palliative systemic therapy: While patients who had radiotherapy during the palliative situation usually initiated systemic therapy (92.2\%), patients who had no

Table 3 Metastatic sites and radiotherapy

\begin{tabular}{lcc}
\hline Metastatic sites & $\begin{array}{c}\text { Number of } \\
\text { patients } \\
\text { (\% of the } \\
\text { study cohort, } \\
\mathbf{n = 3 4 0 )}\end{array}$ & $\begin{array}{c}\text { Number of } \\
\text { patients who had } \\
\text { radiotherapy } \\
\text { (\% of the metastatic } \\
\text { site occurrence) }\end{array}$ \\
\hline Bone & $237(69.7)$ & $108(45.6)$ \\
Lung & $175(51.5)$ & $1(0.6)$ \\
Liver & $149(43.8)$ & $1(0.7)$ \\
Brain & $64(18.8)$ & $55(85.9)$ \\
Lymph nodes (excluding & $97(28.5)$ & $8(8.2)$ \\
ipsilateral locoregional LNs) & & $9(15.0)$ \\
Other locations & $60(17.6)$ & $22(33.3)$ \\
Local recurrence (breast and/or & $66(19.4)$ & \\
ipsilateral locoregional LNs) & &
\end{tabular}

LN: lymph node.

${ }^{1}$ Only cases with local recurrences which were diagnosed and had radiotherapy after the diagnosis of other distant metastases. radiotherapeutic interventions received systemic therapy after the diagnosis of DMD significantly less often $(81.7 \%, p=0.006$; Table 5). With regard to endocrine therapy, the number of patients who had radiotherapy and those who had not was comparable (radiotherapy: $61.7 \%$ vs. no radiotherapy: $57.7 \%, \mathrm{p}=0.149)$. Patients who did not have radiotherapy received palliative chemotherapy less often $(73.3 \%$ vs. $53.7 \%, \mathrm{p}<0.001)$. In cases where palliative systemic therapy was applied, the median number of therapy lines was higher in the group of patients who received radiotherapy ( 3 vs. $2, \mathrm{p}<0.001$; Table 5).

\section{Discussion}

Most of the published studies on radiotherapy in metastatic BC evaluate only therapy options in pre-selected groups of patients with particular metastatic sites and focused on the effect of different fractionation regimens and total radiation doses [4]. In general, there are two different groups of palliative local radiotherapy, namely locoregional therapy of the primary tumor site and/or regional lymph nodes with or without surgery, and radiotherapy at distant anatomic sites:

1. Radiotherapy of the primary tumor site and/or regional lymph nodes with or without surgery Traditionally, locoregional therapy in metastatic $\mathrm{BC}$ was limited to palliative management of uncontrolled disease such as large and ulcerative lesions. However, several retrospective studies indicated that patients who have primary DMD might benefit from the resection of the primary breast lesion in terms of prolonging survival [13-25]. These studies did not systematically consider the role of radiation in improving local control as a therapy concept; some authors did not even report on the rate of radiotherapy in their study cohorts $[13,16,19,21-23]$, and the ones who did reported radiotherapy rates between $0 \%-67 \%$

$[14,15,17,18,20,24,25]$. Le Scodan et al. reviewed the clinical outcome of 581 patients with metastatic BC and focused more on the role of radiotherapy. The authors found that locoregional therapy, mainly consisting of radiotherapy, was also associated with a substantial gain in median survival [26]. In this retrospective analysis, 320 patients received locoregional treatment after diagnosis of DM: the majority of the patients $(n=249,78 \%)$ received exclusively radiotherapy, 41 patients $(13 \%)$ had radiotherapy of the breast or the chest wall after surgical removal of the tumor, and 30 patients (9\%) had surgery alone. The authors found a survival benefit in favor of locoregional treatment of 11 months. The most favorable outcome data 
Table 4 Patient's age at radiotherapy, time of radiotherapy within the disease course of metastatic breast cancer and survival after radiotherapy during the palliative situation

\begin{tabular}{|c|c|c|c|c|}
\hline Metastatic sites: & $\begin{array}{c}\text { A. All cases } \\
255 \text { series (\%) }\end{array}$ & $\begin{array}{c}\text { B. Bone } \\
161 \text { series (\%) }\end{array}$ & $\begin{array}{c}\text { C. Brain } \\
57 \text { series (\%) }\end{array}$ & $\begin{array}{l}\text { D. Local recurrence } \\
\text { (incl. lymph nodes) } \\
22 \text { series (\%) }\end{array}$ \\
\hline \multicolumn{5}{|l|}{ Age (years) } \\
\hline Mean/median & $60.6 / 60$ & $60.5 / 58$ & $55.4 / 57$ & $62.6 / 64.5$ \\
\hline (range) & $(32-89)$ & $(37-89)$ & $(32-80)$ & $(39-86)$ \\
\hline \multicolumn{5}{|l|}{ Phase of DMD } \\
\hline First third & $127(49.8)$ & $88(54.7)$ & $16(28.1)$ & $15(68.2)$ \\
\hline Second third & $44(17.3)$ & $26(16.1)$ & $15(26.3)$ & $2(9.1)$ \\
\hline Last third & $84(32.8)$ & $47(29.2)$ & $26(45.6)$ & $5(22.7)$ \\
\hline \multicolumn{5}{|c|}{ Series performed during: } \\
\hline Last 12 months of life & $135(52.9)$ & $78(48.4)$ & $44(77.2)$ & $8(36.4)$ \\
\hline Last 6 months of life & $95(37.3)$ & $53(32.9)$ & $33(57.9)$ & $5(22.7)$ \\
\hline Last month of life & $29(11.4)$ & $15(9.3)$ & $10(17.5)$ & $2(9.1)$ \\
\hline \multicolumn{5}{|c|}{ Survival after radiotherapy (months) } \\
\hline Mean/median & $17.8 / 10$ & $18.9 / 14$ & $7.6 / 5$ & $23.2 / 21$ \\
\hline (range) & $(0.2-123)$ & $(0.2-121)$ & $(0.2-29)$ & $(0.5-99)$ \\
\hline \multicolumn{5}{|l|}{ Survival, p-values: } \\
\hline A vs. B: 0.318 & B vs. C: $<0.001$ & & & \\
\hline A vs. C: $<0.001$ & B vs. D: 0.346 & & & \\
\hline A vs. D: 0.158 & C vs. D: $<0.001$ & & & \\
\hline
\end{tabular}

(median survival time: 39 months; three-year overall survival rate: $52.6 \%$ ) was achieved by the combined locoregional approach of surgery followed by radiotherapy [26].

Le Scodan and colleagues used a multivariable analysis which controlled for a multitude of possible confounding factors such as age, clinical nodal status, metastatic patterns and use of systemic therapy. However, the hypothesis that improved locoregional tumor control may result in a survival benefit remains controversial because the results of retrospective data might be biased by one crucial confounder, namely the physicians' selection for or against locoregional therapy. To date, no data from randomized trials are available to provide a higher level of evidence regarding the impact of locoregional therapy on survival in $\mathrm{BC}$ patients with primary DMD [4,27] and thus the decision whether or not to integrate breast surgery and/or radiotherapy of the primary tumor site into the palliative therapy concept needs to be done on an individual basis [4].

In our study cohort, the primary tumor was surgically removed at the time of diagnosis in 43 of the 92 patients $(46.7 \%)$ who had primary DMD. From these 43 patients, eight (18.6\%) received postoperative radiation of the breast/chest wall and or locoregional lymph nodes. In three patients, the primary breast lesion was not surgically removed but was later irradiated after tumor progression

Table 5 Palliative systemic therapy and radiotherapy

\begin{tabular}{lcccc}
\hline & $\begin{array}{c}\text { No radiotherapy } \\
\text { (175 patients) }\end{array}$ & $\begin{array}{c}\text { Radiotherapy: all cases } \\
\text { (165 patients) }\end{array}$ & $\begin{array}{c}\text { Radiotherapy: bone } \\
\text { (108 patients) }\end{array}$ & $\begin{array}{c}\text { Radiotherapy: brain } \\
\text { (55 patients) }\end{array}$ \\
\hline No systemic therapy & $32(18.3)$ & $13(7.8)$ & $9(8.3)$ & $6(10.9)$ \\
Chemotherapy (CT) only & $42(24.0)$ & $44(26.7)$ & $24(22.2)$ & $26(47.3)$ \\
Endocrine therapy (ET) only & $49(28.0)$ & $31(18.8)$ & $23(21.3)$ & $3(5.4)$ \\
CT + ET & $52(29.7)$ & $77(46.7)$ & $52(48.2)$ & $20(36.4)$ \\
Median number of systemic therapy lines & $2(1-8)$ & $3(1-10)$ & $3(1-10)$ & $3(1-10)$ \\
\hline
\end{tabular}

CT: chemotherapy; ET: endocrine therapy. 
under systemic therapy (duration of systemic palliative therapy: six months in two patients, twelve months in one patient).

2. Radiotherapy at various distant sites In contrast to locoregional therapy at the primary tumor site, which is mainly performed when DMD is first diagnosed, radiation of distant metastatic sites is usually performed at a later time point in the course of DMD. These cases comprise a highly heterogeneous group of radiotherapeutic interventions. Most studies on this subject evaluated the feasibility of different radiation schedules and outcome data of radiotherapy at the respective metastatic sites [4,7-9], classically the bone and brain, and for spinal cord compression. In doing so, these studies primarily reflect the perspective of one oncological subdiscipline, namely radiation oncology. However, they did not utilize control groups of patients with metastases at the same site who were not radiated, nor take into account the overall course of DMD. Thus, they failed to answer basic questions such as "How many BC patients with bone or brain metastases can be expected to have radiotherapy during their palliative disease course?" or "How are these procedures embedded in the entire disease and therapy course?". These questions require a general oncologic perspective and can only be answered through examination of a cohort of unselected patients with metastatic disease and by thorough analysis of metastatic patterns.

In this study, we applied such a general oncologic approach. Based on a prospective $\mathrm{BC}$ database in which most of the patients who developed DMD were actually recorded (lost to follow-up rate of $<3 \%)$ and in which the vast majority of palliative courses were completely documented with regard to metastatic patterns, systemic therapy, surgery and radiotherapy, we aimed to give a comprehensive overview regarding the totality of all disease-related radiotherapeutic procedures in the palliative $\mathrm{BC}$ situation.

In our study cohort comprised of 340 patients with distant metastatic BC, $48.5 \%$ of the patients had radiation oncology procedures during the palliative disease course. Approximately $50 \%$ of the procedures were performed in the first third of the palliative disease course and the median survival after radiation therapy was 10 months. When interpreting our results, the following limitations of our study must be considered. First, our study comes from a single region of a small country with a high socioeconomic status. Secondly, our study analyzes retrospective data. On the other hand, it is a particular strength of our study that, besides the above mentioned valuable feature of complete documentation of disease course, we included patients who are usually underrepresented in large $\mathrm{BC}$ databases and thus are underreported in the oncologic literature, namely those who did not have any treatment from specialized oncologists, and did not receive surgery, radiotherapy and/or antineoplastic therapy.

The actual clinical use of radiotherapy in $\mathrm{BC}$ is dictated by both the surgeons' and oncologists' knowledge of indications for radiotherapy which determines the referral practice to a radiooncological therapy unit and the therapy principles of the respective unit. The data on radiotherapy in metastatic $\mathrm{BC}$ reported in this study might reflect a certain attitude towards palliative radiotherapy at our institution. In the palliative BC setting, there is currently no standard of care for this heterogeneous group of patients, and treatment decisions are made on an individual basis. In this scenario, it is easy to imagine that particular regional or even site-specific attitudes towards palliative therapy options might influence therapy decisions considerably more than in the adjuvant situation with its more clearly defined and widely accepted therapy guidelines. Thus, the rates of radiotherapeutic procedures reported in this study might vary from those of other cohorts of metastatic $\mathrm{BC}$ patients treated elsewhere.

In cases of metastatic cancer in which palliative therapy results in longer survival times, some essential aspects in the disease course and therapy concept resemble those of chronic non-malignant diseases. Chronic diseases are by definition long-lasting or recurrent and require a long period of treatment, supervision, observation or care; they are caused by non-reversible pathological alterations, leave residual disability, and can be altered but not be cured by various therapies $[28,29]$. Both chronic non-malignant diseases and longer metastatic disease courses require periodic therapy to control progressive course, and symptoms can be treated using strategies that permit stabilization with treatment regimens that have limited cumulative toxicity. There is no generally accepted definition as to how long a disease must last in order to be considered as chronic. In the case of rapidly progressive malignant diseases which lead to death within a few months, this is surely not justified. Undoubtedly, through the introduction of a new generation of effective agents with safer profiles in the last 20 years (e.g., endocrine therapy: third-generation aromatase inhibitors, fulvestrant; chemotherapy: taxanes, capecitabine, liposomal 
doxorubicin, gemcitabine, vinorelbine; immunotherapy: trastuzumab) and of course, through considerable advances in supportive care, longer survival times could be achieved, which in turn allows application of chronic disease treatment concepts in metastatic BC. In this study, which spanned an observation period of more than 20 years, the median MDS was 19 months. Of the 340 metastatic BC patients who ultimately died of the disease, 151 patients (44.4\%) lived for 24 months or longer after diagnosis of DMD. One cannot assess exactly the impact of radiotherapy on increased survival rates in metastatic BC. We have deliberately foregone drawing conclusions regarding the impact of palliative surgery on survival. In addition to the retrospective approach of our study, there is a high degree of heterogeneity within the entire cohort and the described particular subgroups, which would make any analysis regarding palliative radiotherapy and prognostic impact more than debatable. However, compared to rapidly progressive disease courses with short survival times, in cases where a longer MDS was achieved, radiotherapy was significantly more often a part of the multimodal palliative therapy than not: a) in cases with a MDS $\geq 24$ months, $57 \%$ of the patients had radiotherapy during the palliative disease course; b) in the study subgroup of patients who had radiotherapy in the palliative situation, the number of patients who had a MDS $\geq 24$ months was significantly higher compared to those who did not receive radiation (52.1\% vs. $37.1 \%$ ).

\section{Conclusions}

In a cohort of $\mathrm{BC}$ patients who had primary or who developed secondary DMD, nearly one half of the patients received disease-related radiotherapy during the palliative disease course. In the last decade, metastatic cancer has become increasingly viewed as a chronic disease process. In a general palliative therapy approach, which allows for treatment of patients according to the principles of a chronic disease, radiotherapy has a clearly established role in the therapy concept.

\section{Competing interest}

The authors declare that there are no financial or personal relationships with other people or organizations that could inappropriately influence the work reported or the conclusions, implications, or opinions stated.

\section{Authors' contributions}

All authors have made substantial contributions to conception and design of the study (KS, MG, DH, SE, UG), acquisition of data (UG), or analysis and interpretation of data (KS, MG, DH, SE, UG). They have been involved in drafting the manuscript or revising it critically for important intellectual content (KS, MG, DH, SE, UG) and have given final approval of the version to be published (KS, MG, DH, SE, UG). Each author have participated sufficiently in the work to take public responsibility for appropriate portions of the content. All authors read and approved the final manuscript.

\section{Author details}

'Department of Radiation Therapy and Radiation Oncology, Cantonal Hospital Winterthur, Brauerstrasse 15, Winterthur CH-8401, Switzerland. 2Breast Center "SenoSuisse", Brauerstrasse 15, Winterthur CH-8401, Switzerland. ${ }^{3}$ Department of Radiation Therapy and Radiation Oncology, University Hospital Basel (UHB), Petersgraben 4, Basel CH-4031, Switzerland. ${ }^{4} \mathrm{UHB}$, Department of Gynecology and Obstetrics, Spitalstrasse 21, Basel CH-4031, Switzerland. ${ }^{5} U H B$, Institute of Pathology, Schönbeinstrasse 40, Basel CH-4031, Switzerland. ' Department of Gynecology \& Obstetrics, Cantonal Hospital Winterthur, Brauerstrasse 15, Winterthur CH-8401, Switzerland.

Received: 16 February 2014 Accepted: 18 May 2014

Published: 30 May 2014

\section{References}

1. Cardoso F, Harbeck N, Fallowfield L, Kyriakides S, Senkus E, ESMO Guidelines Working Group: Locally recurrent or metastatic breast cancer: ESMO Clinical Practice Guidelines for diagnosis, treatment and follow-up. Ann Oncol 2012, 23(7):vii11-vii19.

2. Cardoso F, Costa A, Norton L, Cameron D, Cufer T, Fallowfield L, Francis $P$, Gligorov J, Kyriakides S, Lin N, Pagani O, Senkus E, Thomssen C, Aapro M, Bergh J, Di Leo A, El Saghir N, Ganz PA, Gelmon K, Goldhirsch A, Harbeck N, Houssami N, Hudis C, Kaufman B, Leadbeater M, Mayer M, Rodger A, Rugo $H$, Sacchini V, Sledge G, et al: 1st International consensus guidelines for advanced breast cancer (ABC 1). Breast 2012, 21:242-252.

3. Pagani O, Senkus E, Wood W, Colleoni M, Cufer T, Kyriakides S, Costa A, Winer EP, Cardoso F, ESO-MBC Task Force: International guidelines for management of metastatic breast cancer: can metastatic breast cancer be cured? I Natl Cancer Inst 2010, 102:456-463.

4. Budach W: Radiotherapy in patients with metastatic breast cancer. Eur J Cancer 2011, 47(Suppl 3):S23-S27.

5. Fujino M, Suzuki K, Nishio M, Nishiyama N, Osaka Y: Strategy of radiation therapy for bone metastases and MSCC in breast cancer patients. Breast Cancer 2011, 18:238-243.

6. Souchon R, Wenz F, Sedlmayer F, Budach W, Dunst J, Feyer P, Haase W, Harms W, Sautter-Bihl ML, Sauer R, German Society of Radiation Oncology (DEGRO): DEGRO practice guidelines for palliative radiotherapy of metastatic breast cancer: bone metastases and metastatic spinal cord compression (MSCC). Strahlenther Onkol 2009, 185:417-424.

7. Foro Arnalot P, Fontanals AV, Galceran JC, Galcerán JC, Lynd F, Latiesas XS, de Dios NR, Castillejo AR, Bassols ML, Galán JL, Conejo IM, López MA: Randomized clinical trial with two palliative radiotherapy regimens in painful bone metastases: 30 Gy in 10 fractions compared with 8 Gy in single fraction. Radiother Oncol 2008, 89:150-155.

8. Rades D, Dunst J, Schild SE: A new scoring system to predicting the survival of patients treated with whole-brain radiotherapy for brain metastases. Strahlenther Onkol 2008, 184:251-255.

9. Roos DE, Turner SL, O'Brien PC, Smith JG, Spry NA, Burmeister BH, Hoskin PJ, Ball DL, Trans-Tasman Radiation Oncology Group, TROG 96.05: Randomized trial of $8 \mathrm{~Gy}$ in 1 versus $20 \mathrm{~Gy}$ in 5 fractions of radiotherapy for neuropathic pain due to bone metastases (Trans-Tasman Radiation Oncology Group, TROG 96.05). Radiother Oncol 2005, 75:54-63.

10. Guth U, Huang DJ, Dirnhofer S, Rochlitz C, Wight E: Distant metastatic breast cancer as an incurable disease: a tenet with a need for revision. Cancer J 2009, 15:81-86.

11. Edge S, Byrd D, Compton C, Fritz AG, Greene FL, Trotti A (Eds): AJCC Cancer Staging Manual. 7th edition. New York: Springer; 2009.

12. Sobin L, Gospodarowicz M, Wittekind C (Eds): UICC: TNM classification of malignant tumors. 7th edition. Oxford: Wiley-Blackwell; 2009.

13. Babiera GV, Rao R, Feng L, Meric-Bernstam F, Kuerer HM, Singletary SE, Hunt KK, Ross MI, Gwyn KM, Feig BW, Ames FC, Hortobagyi GN: Effect of primary tumor extirpation in breast cancer patients who present with stage IV disease and an intact primary tumor. Ann Surg Oncol 2006, 13:776-782.

14. Blanchard DK, Shetty PB, Hilsenbeck SG, Elledge RM: Association of surgery with improved survival in stage IV breast cancer patients. Ann Surg 2008, 247:732-738.

15. Botteri E, Munzone E, Intra M, Bagnardi V, Rotmensz N, Bazolli B, Montanari B, Aurilio G, Sciandivasci A, Esposito A, Pagani G, Adamoli L, Viale G, Nolè F, Goldhirsch A: Role of breast surgery in T1-3 breast cancer patients with synchronous bone metastases. Breast Cancer Res Treat 2013, 138:303-310. 
16. Fields RC, Jeffe DB, Trinkaus K, Zhang Q, Arthur C, Aft R, Dietz JR, Eberlein TJ, Gillanders WE, Margenthaler JA: Surgical resection of the primary tumor is associated with increased long-term survival in patients with stage IV breast cancer after controlling for site of metastasis. Ann Surg Oncol 2007, 14:3345-3351.

17. Gnerlich J, Jeffe DB, Deshpande AD, Beers C, Zander C, Margenthaler JA: Surgical removal of the primary tumor increases overall survival in patients with metastatic breast cancer: analysis of the, 1988-2003 SEER data. Ann Surg Oncol 2007, 14:2187-2194.

18. Hazard HW, Gorla SR, Scholtens D, Kiel K, Gradishar WJ, Khan SA: Surgical resection of the primary tumor, chest wall control, and survival in women with metastatic breast cancer. Cancer 2008, 113:2011-2019.

19. Khan SA, Stewart AK, Morrow M: Does aggressive local therapy improve survival in metastatic breast cancer? Surgery 2002, 132:620-626. discussion 626-627.

20. Neuman HB, Morrogh M, Gonen M, Van Zee KJ, Morrow M, King TA: Stage IV breast cancer in the era of targeted therapy: does surgery of the primary tumor matter? Cancer 2010, 116:1226-1233.

21. Pathy NB, Verkooijen HM, Taib NA, Hartman M, Yip CH: Impact of breast surgery on survival in women presenting with metastatic breast cancer. Br J Surg 2011, 98:1566-1572.

22. Rapiti E, Verkooijen HM, Vlastos G, Fioretta G, Neyroud-Caspar I, Sappino AP, Chappuis PO, Bouchardy C: Complete excision of primary breast tumor improves survival of patients with metastatic breast cancer at diagnosis. J Clin Oncol 2006, 24:2743-2749.

23. Rashaan ZM, Bastiaannet E, Portielje JE, van de Water W, van der Velde $S$, Ernst MF, van de Velde CJ, Liefers GJ: Surgery in metastatic breast cancer: patients with a favorable profile seem to have the most benefit from surgery. Eur J Surg Oncol 2012, 38:52-56.

24. Ruiterkamp J, Ernst MF, van de Poll-Franse LV, Bosscha K, Tjan-Heijnen VC, Voogd AC: Surgical resection of the primary tumour is associated with improved survival in patients with distant metastatic breast cancer at diagnosis. Eur J Surg Oncol 2009, 35:1146-1151.

25. Shien T, Kinoshita T, Shimizu C, Hojo T, Taira N, Doihara H, Akashi-Tanaka S: Primary tumor resection improves the survival of younger patients with metastatic breast cancer. Oncol Rep 2009, 21:827-832.

26. Le Scodan R, Stevens D, Brain E, Floiras JL, Cohen-Solal C, De La Lande B, Tubiana-Hulin M, Yacoub S, Gutierrez M, Ali D, Gardner M, Moisson P, Villette S, Lerebours F, Munck JN, Labib A: Breast cancer with synchronous metastases: survival impact of exclusive locoregional radiotherapy. J Clin Oncol 2009, 27:1375-1381.

27. Ruiterkamp J, Ernst MF: The role of surgery in metastatic breast cancer Eur J Cancer 2011, 47(Suppl 3):S6-S22.

28. Lubkin I, Larsen P: Chronic Illness. Jones \& Bartlett: Sudbury, MA; 2002.

29. Norris S, Glasgow R, Engelgau M, O'Connor P, McCulloch D: Chronic disease management: a definition and systematic approach to component interventions. Dis Manag Health Outcome 2003, 11:477-488.

doi:10.1186/1748-717X-9-126

Cite this article as: Steinauer et al: Radiotherapy in patients with distant metastatic breast cancer. Radiation Oncology 2014 9:126.

\section{Submit your next manuscript to BioMed Central and take full advantage of:}

- Convenient online submission

- Thorough peer review

- No space constraints or color figure charges

- Immediate publication on acceptance

- Inclusion in PubMed, CAS, Scopus and Google Scholar

- Research which is freely available for redistribution

Submit your manuscript at www.biomedcentral.com/submit
Ciomed Central 